\title{
ESTUDOS DA INFÂNCIA, ESTUDOS DA CRIANÇA: QUAIS CAMPOS? QUAIS TEORIAS? QUAIS QUESTÕES? QUAIS MÉTODOS?
}

\author{
Maria Carmen Silveira Barbosa \\ Universidade Federal do Rio Grande do Sul (UFRGS), Porto Alegre, \\ Rio Grande do Sul, Brasil \\ Ana Cristina Coll Delgado \\ Universidade Federal de Pelotas (UFPel), Pelotas, Rio Grande do Sul, \\ Brasil \\ Catarina Almeida Tomás \\ Universidade do Minho (U. Minho), Braga, Portugal
}

\begin{abstract}
RESUMO: Neste artigo realizamos um ensaio teórico sobre os Estudos da Infância e da Criança desde seus primórdios, até sua organização enquanto campos situados na intersecção entre disciplinas e questionamentos sobre infância e crianças. Inicialmente refletimos sobre os conceitos de infância e criança. Em seguida situamos os primórdios dos referidos estudos, com destaque para questões conceituais debatidas no início do século XX e, posteriormente, focalizamos os desafios dos Novos Estudos da Infância e da Criança, como a articulação entre saberes e disciplinas e a diversidade de tradições teóricas. Como são mais recentes as investigações com crianças pequenas, algumas reflexões são propostas e finalizamos com desafios como pensar a rigidez das fronteiras entre gerações e fases da infância.

Palavras-Chave: Infância. Crianças. Estudos da Infância. Estudos da Criança.
\end{abstract}


INTRODUÇÃO

Este artigo é um ensaio teórico sobre os Estudos da Infância e Estudos da Criança desde seus primórdios, precursores e apostas teóricas e metodológicas, até sua organização enquanto campos situados na intersecção entre disciplinas e questionamentos sobre infância e crianças.

Na primeira seção, desenvolvemos reflexões sobre os conceitos de infância e crianças, embora reconhecendo que há limites para definirmos precisamente o que estas categorias significam. Na continuidade situaremos os primórdios dos Estudos da Infância e da Criança, com destaque para algumas áreas das ciências sociais e humanas, seus autores e questões conceituais debatidas no início do século XX e que, posteriormente, foram retomadas criticamente pelos Novos Estudos da Infância e da Criança a partir das décadas de 70 e 80, com problematizações epistemológicas, metodológicas e éticas. Este será o foco principal da terceira seção do artigo, que situa os desafios atuais do campo, entre eles a articulação de zonas de contato entre saberes e disciplinas e as tensões e diversidades de tradições teóricas.

Na quarta seção refletimos brevemente o processo de socialização em direção a ser criança e suas conexões com as culturas da infância. Finalizamos o ensaio com alguns desafios dos Estudos da Criança e da Infância, entre eles: pensar a rigidez das fronteiras entre as diferentes gerações e fases da infância, a necessidade de um contínuo diálogo e movimento teórico - tendo em vista a complexidade dos campos e o entendimento multívoco sobre as crianças, mais sensível às suas diversidades de ação e pensamento.

INFÂNCIA E CRIANÇA(S): CONCEITOS MARCADOS POR AMBIGUIDADES

Para iniciar, lembramos que as tentativas de afirmar um significado único e consensual sobre o que caracteriza a infância e as crianças são continuamente questionadas em diversas áreas do conhecimento, pois infância é um conceito instável, ambíguo, ambivalente e difícil de normatizar. Das crianças e suas vidas podemos dizer o mesmo. A antropóloga Clarice Cohn (2005) assevera que, embora sejam termos assimilados aos nossos conhecimentos, infância e criança são conceitos controversos e de difícil compreensão. Sobre 
a infância, o sociólogo Alan Prout (2010) observa que, longe de ser uma categoria estável e fixa, ela é híbrida, com presença de fatores humanos e não humanos, discursivos e coletivos, que participam da sua definição.

Os sociólogos portugueses, Manuel Jacinto Sarmento e Manuel Pinto, traçam minimamente a diferença entre os significados de infância e crianças. Como esclarecem os autores,

[...] crianças existiram sempre, desde o primeiro ser humano, e a infância como construção social - a propósito da qual se construiu um conjunto de representações sociais e de crenças e para a qual se estruturaram dispositivos de socialização e controlo que a instituíram como categoria social própria existe desde os séculos XVII e XVIII (SARMENTO; PINTO, 1997, p.11).

Pela obra do historiador Philippe Ariès (1986), sabemos que a infância é uma categoria histórica e que, em alguns períodos, as crianças não se distinguiam claramente dos adultos e com eles partilhavam diferentes atividades $\mathrm{e}$ rotinas. A infância tem uma duração bastante variável em distintas sociedades e não é fácil teorizar sobre a infância e as crianças sem considerar os contextos estruturais, condições e tempos onde se inserem. Como afirma Santos (1988, p.141): "todos os conceitos têm contextura espacial, física e simbólica".

Em alguns contextos socioculturais, os rituais de transição são bem definidos e a infância geralmente termina no momento biológico de mutação do corpo. Em outros países, desde o início do século XX, a definição de infância foi se constituindo a partir de negociações com bases e medidas legais, pois as crianças eram e ainda são vítimas de vários abusos. Por conseguinte, com a Declaração dos Direitos da Infância (1959)', inicia-se o processo de constituição da criança concebida como sujeito de direitos, processo que será aprofundado com a Convenção dos Direitos da Criança (CDC, 1989)² em que foi estabelecido um texto jurídico adotado pela Assembleia Geral das Nações Unidas que exigiu que seus países membros passassem, pelo menos do ponto de vista teórico e simbólico, a cumprir o que está plasmado nesse documento. Mais ainda, assistimos a um maior distanciamento entre crianças e adultos e a qualificação das crianças em função das suas idades A CDC (1989) considera que uma criança é"todo o ser humano menor de 18 anos, salvo se, nos termos da lei que lhe for aplicável, atingir a maioridade mais cedo" (CDC, Art. 1, 1989). 
No Brasil, o Estatuto da Criança e do Adolescente (ECA), 1990, instituiu que a infância dura até os 12 anos. Depois esse ser humano passa a ser denominado de adolescente, nos textos mais voltados à psicologia, ou jovem, no campo da sociologia. O período prolongado pode também levar a pensar que a infância possui divisões intrageracionais, constituídas por subgerações dentro deste todo maior que é a geração infância (FERNANDES, 2008). Portanto, um desafio posto para a sociedade e os estudos acadêmicos é constituir outras formas de pensar a rigidez das fronteiras entre as diferentes fases da infância.

Pelos estudos de Ariès (1986) - historiador referido anteriormente - $\mathrm{e}$ Norbert Elias (2011) - sociólogo alemão -, sabemos que no século XVII houve, na Europa, uma forte separação entre o mundo dos adultos e o mundo das crianças, via processo civilizatório.

Como refere Barbara Rogoff (2005), estudiosa da Psicologia Cultural, as demarcações da idade são baseadas em uma perspectiva cultural. Com o surgimento da industrialização e os esforços para sistematizar serviços como educação e atendimento médico, a idade se tornou uma medida de desenvolvimento e um critério para classificar as pessoas. Em vez de manter-se vinculadas ao mundo adulto, as crianças passaram a se envolver mais em práticas sociais e instituições especializadas em crianças.

Algumas provocações parecem pertinentes: o que define um bebê, uma criança pequena ou uma criança mais velha? Como recortar estes distintos modos de ser criança? Deveríamos continuar a tentar uma conceitualização geral ou, como dizem Alma Gottlieb (2009) - antropóloga - e Rogoff (2005), optar em compreender a infância localmente, no âmbito de uma cultura específica? Para Gottlieb (2009), a ideia de "primeira infância" não pode ser compreendida no âmbito de uma certeza biológica, mas como uma construção cultural ocidental, cujo início e término variam em diferentes grupos sociais.

As denominações "primeira infância" ou "pequena infância" também são contestadas por sociólogos da infância, pois consideram esses recortes como arbitrários e dependentes dos dispositivos institucionais voltados para a infância, das representações que a elas estão associadas e do "mercado" pro- 
fissional orientado para uma determinada faixa etária que define o ingresso das crianças na educação obrigatória (PLAISANCE, 2004, p. 222).

As denominações "primeira infância" ou "pequena infância" também são contestadas por estudiosos da infância (GOTTLIEB, 2009; PLAISANCE, 2004), pois consideram esses recortes como arbitrários e dependentes dos dispositivos institucionais voltados para a infância, das representações que a elas estão associadas e do "mercado" profissional orientado para uma determinada faixa etária que define o ingresso das crianças na educação obrigatória (PLAISANCE, 2004, p. 222).

Se a definição de infância e de crianças não é muito simples, as relações das crianças entre elas e o papel que o encontro, o convívio e os relacionamentos têm do ponto de vista social e individual, são especialmente importantes para que conheçamos seus critérios de pertencimento em alguns grupos, quase nunca marcados pelas faixas de idade, uma vez que esses critérios são demarcações adultocêntricas - problemática que demanda mais investigações nos Estudos da Infância e da Criança. As reflexões iniciais mostram, de fato, que não está tudo dito sobre a infância e as crianças, muito longe disso. Em suma, podemos afirmar que conhecer a infância e as crianças é uma tarefa complexa. Contudo, para o sociólogo Boaventura de Sousa Santos, "não será através de perguntas complexas, mas sim de perguntas simples, que encontraremos o significado dessa complexidade enquanto orientação para a ação" (SANTOS, 1988, p. 4).

PRESSUPOSTOS, PRIMÓRDIOS E QUESTÕES CONCEITUAIS DOS ESTUDOS DA INFÂNCIA E ESTUDOS DA CRIANÇA

Os Estudos da Infância e os Estudos da Criança são compreendidos como campos de intersecção entre disciplinas e questionamentos sobre as características ou os atributos da infância nos distintos momentos vividos nos anos iniciais da vida, embora saibamos que estas etapas não são estáveis e suas representações mudam no tempo e no espaço. Como todos os campos interdisciplinares, os Estudos da Infância (conceitual) e os Estudos da Criança (aqui e agora) compartilham um mesmo objeto de estudos, porém vistos por perspectivas muito diferenciadas. As diferenças podem advir da tradição 
disciplinar, isto é, aquilo que diferencia a definição do objeto de estudo e sua metodologia de investigação, e, podem advir, também, da perspectiva teórica que define os conceitos, as metodologias de pesquisa e a análise dos dados.

Se os Estudos da Criança têm como base metodológica entrevistas, brincadeiras, desenhos, filmagens, fotografias - que são modos diretos de observação e descrição densa, no sentido atribuído pelo antropólogo Clifford Geertz (1989) -, os Estudos da Infância caracterizam-se por procurarem compreender sobre as crianças a partir de dados não especialmente gerados por elas, mas por estudarem os artefatos que produzem e que medem as infâncias.

De acordo com Martin Woodhead (2004), o surgimento e o desenvolvimento dos Estudos da Criança constroem-se a partir de duas dimensões:

a) Nascem da frustração das versões "estreitas" sobre a criança, que são oferecidas pelos discursos acadêmicos, e, das metodologias de investigação "dominantes", que consideram as crianças como objetos ou fonte de dados. O apelo face aos Estudos da Criança, que advogam a interdisciplinaridade, significa uma abordagem integrada da investigação e a tentativa em conseguir "alcançar" as vidas das crianças e o seu bem-estar a partir das suas vozes.

b) Constroem-se em torno da rejeição do "essencialismo" que é endêmico na teorização tradicional sobre a infância e as crianças. Ao invés, defende-se o reconhecimento das múltiplas formas em que a infância é socialmente construída e reconstruída em relação a uma multiplicidade complexa de dimensões, como tempo, espaço, idade, gênero, etnia, classe social, etc. Desta forma, considera que é possível desocultar o que tem sido "escondido" e naturalizado na vida das crianças, o que remete para uma análise social, histórica e culturalmente construída, portanto, também política.

Não obstante, o campo está longe de uma unificação metodológica, teórica ou uma única definição de como o conhecimento sobre a infância e as crianças é constituído. Afinal, seu objetivo é apreender o campo de estudos em seu contínuo mapeamento e diálogo. Como qualquer outro sistema institucionalizado de práticas sociais, é uma realidade em movimento contínuo, 
heterogêneo, multideterminado, de dentro e de fora do campo. No entanto, pode ser identificado um conjunto de pressupostos comuns ao campo dos Estudos da Criança e dos Estudos da Infância: a centralidade da criança na investigação; a alteridade infantil; a dimensão geracional; e, o caráter interdisciplinar da investigação com crianças.

Para compreendermos a emergência dos dois campos (Estudos da Criança/Estudos da Infância) há três momentos importantes a destacar: (1) O momento inicial onde a medicina e a psicologia estão atentas a este novo e pouco conhecido objeto de conhecimento e procuram, no âmbito das ciências positivas, examiná-lo. E as contribuições da pedagogia, que a partir de um conceito de infância, muitas vezes idealizado, procura conhecer e educar as crianças, almejando formá-las neste modelo;

(2) o segundo momento, que nasce no bojo dos processos sociais dos anos de 1970 e 1980, que reivindica para a criança a potência de sujeito político; (3) um terceiro momento, onde nas ciências sociais, especialmente na sociologia da infância, na antropologia da infância e na geografia da infância, procuram conhecer as crianças com metodologias mais próximas da etnografia e das metodologias participativas.

Quanto ao momento inicial, marcado pela medicina, psicologia e pedagogia, destacamos que discursos e práticas foram contribuindo para uma construção da norma da infância e, com mais intensidade nos séculos XVIII e XIX, pedagogos, psicólogos, assistentes sociais e médicos contribuíram para a afirmação desta norma definindo modos de educação, de aprendizagem e de desenvolvimento infantil com vistas a uma modelagem do que seria a infância ideal em direção a adultez.

Por outro lado, também é possível afirmar que os precursores dos Estudos da Infância e dos Estudos da Criança foram autores clássicos da pedagogia, como Rousseau, Pestalozzi, Froebel e, posteriormente, Decroly, Piaget e Montessori, que defendiam ideias de que as crianças eram o centro dos processos educacionais. Julie Delalande (2007; 2009), também enfatiza que o nascimento desses estudos não pode ser compreendido independentemente do desenvolvimento das pedagogias novas que já perspectivavam a ideia de uma socialização horizontal entre crianças. 
Como salienta Barbosa (2014), a armadilha desta "pré-história" dos Estudos da Infância e da Criança foi a busca de uma essência do ser infantil, da universalidade da infância, da linearidade no comportamento das crianças e do estabelecimento de parâmetros de normalidade, com uma concepção evolutiva do desenvolvimento humano vinculada à ideia de ciência positiva da passagem do século XIX para o XX. Porém, se alguns educadores procuravam sistematizar os conhecimentos sobre as crianças, na perspectiva da construção de uma ciência da infância universal, certamente é possível sustentar que a presença das crianças, o convívio direto destes investigadores nas instituições nas quais as crianças eram cuidadas e educadas e suas ações frente ao mundo social levavam os pedagogos a pensar também no seu exercício de singularidade. Educadores ligados às crianças, aqueles que com elas efetivamente trabalhavam, tal como Januz Korczak, no início do século passado sustentaram, com suas lutas políticas e sociais, a ideia de uma carta de Direitos das Crianças (DALLARI, 1986).

Roger Cousinet, pedagogo francês, publicou em 1950 um "ensaio de sociologia infantil" com ênfase nas sociedades infantis, evitando centralidade em análises psicológicas e pedagógicas. Para ele, as crianças constituem seus grupos espontaneamente, principalmente quando não cerceadas pelos mestres. Este autor definia a socialização como uma parte do desenvolvimento da vida mental, intelectual e afetiva da criança e recusava sua redução a uma simples adaptação social. Neste sentido, ele defendia a observação refinada das brincadeiras das crianças pelo cruzamento da pedagogia, da etnologia e da sociologia (OTTAVI, 2009, p.12). Conforme estudos de Dominique Ottavi, ele foi o inventor da sociologia da infância, porque tentou compreender as leis e regras criadas pelos grupos de crianças, nos momentos de jogo e também fora destes contextos e com uma observação que acolhia a alteridade infantil. Inventor do trabalho livre por grupos, ele se interessou pela criança brincante, que luta pelo seu território frente ao emprego do tempo e das atividades impostas pelo adulto (OTTAVI, 2009, p.16).

"[...] a criança que entra na escola está em contato não somente com seus coetâneos - os recreios reúnem crianças de diferentes anos e portanto de idades muito diferentes - mas com outros maiores que ele, a quem não 
conhecem e não conhecerão, talvez, jamais. Não os conhece mas observa, os assiste jogar e aprende a fazer o que eles fazem" (COUSINET, 1953, p. 36).

E para Delalande (2012), outras perspectivas de desenvolvimento e aprendizagem já despontavam no início do século XX, como a do antropólogo Marcel Mauss (2010) que sustentava em uma conferência de 1937, que existe uma educação das crianças pelas próprias crianças e que quando elas brincam juntas formam um ambiente que tem sua moral, suas regras de jogo, sua força.

Considerado o criador da etnologia francesa, Van Gennep (1943 apud DELALANDE, 2009), foi um dos primeiros a apresentar o universo das crianças em sua dimensão cultural e social percebendo a socialização horizontal, ou seja, para ele a educação das crianças se fazia, sobretudo, com as outras crianças, por um contrato moral e imitativo (DELALANDE, 2009).

No campo da Antropologia, alguns dos autores supracitados e outros, nas décadas de 1930 a 1950, se utilizaram de dados etnográficos e passaram a desconstruir a criança universal. É o caso da antropóloga americana Margareth Mead, que por um estudo comparativo entre sua própria sociedade e as "sociedades simples", situadas na Nova Guiné, buscava compreender como a cultura modela o indivíduo e como etapas da vida marcadas por fenômenos psicológicos são tratadas diferentemente por cada cultura (DELALANDE, 2009). Ela recolhia dados etnográficos sobre a infância em sociedades não ocidentais, através de observação participante, filmagens e fotografias constituindo, segundo a socióloga Manuela Ferreira e a antropóloga Ângela Nunes (2014), um grande acervo sobre crianças e adolescentes.

No caso dos estudos antropológicos no Brasil, Aracy Lopes da Silva e Ângela Nunes (2012) constatam que não havia interesse focado nas crianças e infância, pois as temáticas predominantes eram as de parentesco e religião, que foram aproveitadas para reconstituir a vida das crianças, inclusive por antropólogos que tinham artigos publicados sobre outros temas, embora com observações que indiretamente faziam aparecer as crianças.

Contrariamente ao que parece tão óbvio e tão fácil de responder, um olhar atento à literatura produzida sobre as sociedades indígenas no Brasil deixará evidente que assim não o é. Nos surpreende o fato de que as informações sobre o universo das crianças indígenas são raras na bibliografia antro- 
pológica brasileira, exceto quando ocasional e secundariamente [...] mais surpreendidos ficamos ao constatar que essa ausência verifica-se em muitos outros domínios das ciências sociais, tomadas globalmente e no decorrer de todo um século. (SILVA; NUNES, 2012, p.12).

Podemos afirmar que esses autores filiados à sociologia, pedagogia, filosofia, etnologia e antropologia contribuíram para o surgimento de teorias, métodos e questões nos primórdios dos estudos da infância e das crianças. Essa foi uma importante articulação teórico-metodológica, pois na medida em que as investigações exigiam uma relação mais intensa com as crianças, as respostas das mesmas e os seus modos de implicar-se nos processos de produção de dados efetivamente auxiliavam a constituir discursos teóricos sobre a infância. Por exemplo, a partir da prática de pesquisa participativa com crianças foi constituída a elaboração do conceito de agência e de participação das crianças (TOMÁS, 2011).

OS NOVOS ESTUDOS DA INFÂNCIA E OS NOVOS ESTUDOS DA CRIANÇA: QUAIS CAMPOS, QUESTÕES, TEORIAS E MÉTODOS?

Uma consideração importante, seja nos Novos Estudos da Criança ou nos Novos Estudos da Infância, é que a sua constituição, na década de 80, assim inseridos num período de crítica a uma ciência positiva, de revisão de reflexões pouco hegemônicas sobre a infância possibilitou que desde seus inícios tivessem uma dimensão mais contemporânea de pesquisa, indagando a possibilidade de verdade científica e método único. Portanto, a construção do campo dos Novos Estudos da Infância já se faz a partir de uma ciência crítica, isto é, eles emergem no campo das perspectivas críticas que não procuram estabelecer generalizações sobre o tema da infância, mas constituir um conhecimento situado e de possíveis relações disciplinares. A partir das análises sobre as crianças tecem-se considerações seja no momento de conhecer a história da infância em diferentes tempos e espaços ou ao conceituar o que é, politicamente, uma criança. Estes estudos remetem à possibilidade, no contexto de construção social de uma ciência, de criar estabilidades e referências, mas não de verdades estanques. 
Nos Novos Estudos da Criança a intenção é possibilitar o encontro com as crianças situadas contextualmente, escutá-las, traduzi-las e afirmá-las como um ato de liberdade. Construir, a partir das crianças, outras imagens de infância que conduzam a perspectivas mais locais a partir da descrição, da escuta da voz e da participação das mesmas. É a definição de um pensamento novo sobre os seres humanos de pouca idade. Como explica Sarmento (2013), os Novos Estudos da Criança possuem um caráter de resistência frente aos processos de dominação que ocultam as crianças. Ele reivindica que se adote uma diversidade de contextos e práticas sociais para além das pesquisas com crianças das classes médias, em suas escolas e famílias e nos países centrais, e, que se foque a centralidade dos estudos na criança, na completude das suas possibilidades. Por conseguinte, a criança não é o adulto imperfeito e imaturo, mas é o Outro do adulto, isto é, entre a criança e o adulto há uma relação não de incompletude, mas de alteridade (SARMENTO, 2013, p.18-19).

Na filosofia, é possível compreender as duas perspectivas levantadas acima. A Filosofia da Infância procura a compreensão sobre a Infância como uma temporalidade desvinculada das etapas da vida e afirma a infância como condição dos sujeitos, sendo essa mais uma dimensão do que uma etapa da vida, portanto lida com uma infância conceitual. A Filosofia da Criança, ou ainda a Filosofia para ou com as Crianças, está atenta aos sujeitos como seres que vivem uma etapa de sua vida e provoca a indagação por uma educação definida para aqueles que atualmente habitam a infância, para fazê-los partícipes de um mundo comum (MATTHEWS, 1997; KOHAN, 2003).

Assim, para compreendermos a situação da infância como categoria social, permanente da sociedade, é preciso estudar dados amplos e de modo estrutural, para ver como a infância vai se conformando histórica e socialmente. Torna-se fundamental elaborar estudos quantitativos em escala mundial, pois estes resultados incidem em políticas públicas que mudam (ou não) vidas singulares. A análise feita por Jens Qvortrup (2014), referência nos Estudos da Infância, é estrutural, macro, no campo da demografia e da economia, mas, em nenhum momento, podemos chamá-la de estruturalista. Os sujeitos analisados têm agência e a estrutura é pensada como historicamente construída. Ser estrutural não significa ser estruturalista. As teorias sociais 
e macroeconômicas - em toda a sua diversidade discursiva - são as que podem explicitar os fenômenos desta intensidade. Talvez para a ampliação e aprofundamento do campo, o importante seja poder combinar o macro e o micro, o local e o global, nos Estudos da Infância e da Criança.

As perspectivas interpretativas e críticas, que deram vigor às investigações com crianças e as teorizações sobre a infância, demonstram o quanto a abordagem estruturalista que definiu, com força, a sociologia francesa, não teve grande sucesso no campo da investigação sobre a infância ou com crianças.

Essas abordagens construíram a metodologia qualitativa que forma a base da antropologia, com objetivo de estudar a agência das crianças, descrever, observar e seguir a ação para compreender as crianças, como atores sociais, no estudo de conceitos como reprodução interpretativa e a centralidade das culturas de pares (CORSARO, 2011; SIROTA, 2011). Quanto aos conceitos de agência, ação e ator social, Régine Sirota (2011) identifica a criança como ator social no mundo francófono e a agência da criança no mundo anglófono. Não são termos equivalentes, pois a agência toma uma noção mais ampla, porque não se trata apenas da capacidade de ação social da criança, mas subentendem-se os efeitos dessa mesma ação na definição da situação para os diferentes atores.

As perspectivas críticas que romperam fundamentalmente com o pensamento positivista constituíram um campo fértil de trabalhos para pensar a infância como construção sócio-histórica e a constituição da criança como sujeito. Elas mantêm-se fortemente ligada à ideia de empoderamento, emancipação e interdependência da infância com a adultez.

Partindo do conceito de Walter Mignolo de descolonização (2003), defendemos aqui a ideia de que estamos a assistir a um processo de descolonização da infância (TOMÁS, 2011). Não se trata apenas de defender a libertação das crianças, com vista à sua formação e reconhecimento como categoria social autônoma e isolada, mas de um processo de descolonização epistêmica, de socialização do conhecimento sobre a infância e as crianças e dos fundamentos adultocêntricos da racionalidade. Pretende-se combater a ideia da não racionalidade das crianças perspectivando a infância como uma categoria social específica, mas não isolada e separada do todo social. 
Com especial incidência na última década, podemos identificar um conjunto de debates que se realizam dentro do campo (ALANEN, 2011). Primeiro, a necessidade de ultrapassar algumas das "velhas-novas" dicotomias que têm obstaculizado o avanço da reflexão, nomeadamente: homogeneidade versus heterogeneidade da infância; adulto(s) versus criança(s); agência versus estrutura. Mais ainda, urge ultrapassar o domínio da Sociologia da Infância nos Estudos da Criança.

Dessa forma, podemos identificar alguns desafios atuais do campo: (1) a necessidade de densificação da estrutura multi e interdisciplinar e promover zonas de contato entre saberes e disciplinas (PROUT, 2010; SARMENTO, 2008; ALANEN, 2011;); (2) a desocultação das linhas fraturantes no que se pensou anteriormente ser um projeto unificado, refletindo tensões entre áreas-chave e posicionamentos teóricos do campo - a socióloga Leena Alanen chega mesmo a propor, por exemplo, o desenvolvimento dos Estudos da Criança Críticos; (3) Refletir sobre a diversidade de denominações existentes quando nos referimos ao campo: Child Studies, Childhood Studies, Children Studies, New Social Studies of Childhood, Early Childhood Studies ou Social Studies for Early Childhood, este último desafio mostra como "a definição continua aberta ao debate" (ALANEN, 2011, p.147).

Entre a tradição francófona e a tradição anglo-saxônica podemos afirmar a existência de um ilhéu, "o pólo lusófono" como denomina Sirota (2011) ou o "incomum" como o faz Sarmento (2013). Não se trata aqui de apresentar este polo na perspectiva do isolamento, mas o entendimento da ilha como "um permanente cais de embarque, nem que seja do pensamento" (PAIS, 2002). Nas últimas duas décadas, assistimos a encontros entre Portugal-Brasil, sobretudo no diálogo entre a Sociologia da Infância e a Pedagogia, que potenciou o desenvolvimento de intercâmbios e o avanço no campo dos Estudos da Criança. Não se trata igualmente de afirmar a emergência de um subcampo, de uma espécie de Estudos da Criança e Estudos da Infância luso-brasileiros, mas a necessidade de compreender um jogo de (in)visibilização quando utilizamos paradigmas e conceitos do mundo anglo-saxônico para, por exemplo, analisar e explicar a realidade das crianças em Portugal ou no Brasil. 
O exercício centrado na reflexão de pressupostos relativos aos processos de socialização em direção a ser criança e suas conexões com as culturas da infância possibilita explicitar alguns desafios concernentes aos estudos com crianças pequenas.

\section{UMA SOCIALIZAÇÃO EM DIREÇÃO A SER CRIANÇA: CONEXÕES COM CULTURAS DA INFÂNCIA}

Em artigo sobre a socialização da pequena infância, Éric Plaisance (2004) propõe o entendimento desse conceito também como resultante das relações horizontais entre pares. Entretanto, essa socialização entre pares ainda permanece invisível nas escolas infantis, posto que ainda é forte o discurso de que as crianças pequenas vão para contextos educativos, formais e não formais, para que se socializem e aprendam a viver coletivamente sob a tutela dos adultos, processo compreendido como vertical, do adulto sobre a criança, um ser associal. Ocorre que estudiosos contemporâneos como Plaisance e outros do início do século XX, como Cousinet (1953), ensinam pelas suas pesquisas que as crianças criam suas regras de convívio social, na qual a dimensão afetiva é forte, onde códigos relacionais se abrem para a construção das identidades sociais entre elas (PLAISANCE, 2004), nem sempre mediadas pela ação dos adultos.

Para o sociólogo Michael-Sebastian Honig (2009), a primeira obra de Chris Jenks (1982) propõe a desconstrução da problemática de socialização, que coloca a questão da criança em termos de um ser humano que ainda não é adulto, ou seja, em termos do seu déficit. Jenks (1982) criticou este paradigma de socialização focado nas distinções entre crianças e adultos, propondo análise dos modos que marcam as diferenças entre as crianças e os adultos, assumindo a criança como o "outro" (CHRISTENSEN, 1994). Como refere Honig (2009), a proposição de Jenks não é de rejeição do paradigma da socialização, mas antes, uma desnaturalização do paradigma da socialização que significa uma socialização em direção a ser criança e não em direção à adultez.

Voltando às definições de infância e crianças, reiteramos a afirmação de que essas só podem ser compreendidas no plural, abrangendo variados 
condicionamentos socioculturais, relações de classe, gênero, idade, etnia e o reconhecimento da existência de culturas da infância. As culturas da infância não são estanques, ao contrário, são móveis, híbridas, mestiças, no sentido proposto pelo historiador francês Serge Gruzinski (2001).

Reivindicar esses aspectos para a compreensão e a valorização das culturas da infância é lembrar que as crianças sempre foram responsáveis pela integração cultural das demais crianças, sendo suas companheiras privilegiadas em grande parte da história humana (ROGOFF, 2005).

Com base nos estudos da criança, meninas e meninos são sujeitos produtores de culturas, uma vez que sua agência tem desdobramentos entre os grupos de pares, via aproximações, amizades, brincadeiras, empatia, conflitos. Todas estas interações possibilitam o desenvolvimento dos processos de construção social de sentidos acerca do que as rodeia (espaço, tempo, regras e saberes), o que é sempre mais complexo do que eventualmente possamos pensar. O adulto terá que adotar uma postura de observação, questionamento e reflexão constantes para conseguir captar esta produção cultural a partir deles.

Delalande $(2009 ; 2012)$ também reflete sobre questões éticas e metodológicas nas pesquisas com crianças e propõe uma subversão das representações de poder, uma vez que crianças pequenas também transmitem saberes aos pesquisadores. Uma forte aposta da referida autora (DELALANDE, 2009) é de que as crianças se apropriam dos lugares que os adultos Ihes destinam, como o pátio de recreação ou os quartos infantis. E acrescentamos, ainda, as salas de referência, as brinquedotecas, as praças e os parques infantis, que adquirem outros significados assim que elas os ocupam para além do que foi projetado pelos adultos.

\section{CONSIDERAÇÕES FINAIS}

Como já referimos, o pensamento moderno é marcado pela proliferação de dicotomias como estrutura versus agência; local versus global; identidade versus diferença; continuidade versus mudança; ser e devir; cultural e biológico; adultos versus crianças; entre outras (PROUT, 2010). O que pode impedir que os estudos das crianças e da infância sejam mais abertos 
ao hibridismo, às suas ambiguidades e instabilidades, pois a consideração dos fatores humanos e não humanos, discursivos e coletivos (PROUT, 2010), que participam das definições de infância e crianças, é indiscutível.

As visões binárias da sociedade vêm sendo problematizadas no campo dos estudos sociais e educacionais desde a década de 90. Por exemplo, Barbosa (2014) analisa a importância de neste final da modernidade ou na modernidade tardia percebermos que não haverá uma solução única, uma escolha de isto ou aquilo, pois é na tensão ativa entre diferentes elementos que podemos elaborar respostas diversas e singulares.

São muitos os desafios postos para a sociedade e para nossas pesquisas, entre eles o de constituir outras formas de pensar a rigidez das fronteiras entre as diferentes gerações e fases da infância. Um padrão alternativo aos binarismos e dicotomias que separam as gerações seria mais horizontal, com indivíduos de diferentes gerações e subgerações sendo conjuntamente responsáveis pelo grupo. Nesse, os indivíduos não são controlados por outros - a autonomia individual para a tomada de decisões é respeitada -, mas também se espera que funcionem em sintonia com a direção do grupo (ROGOFF, 2005). Para Rogoff (2005), o entendimento da diversidade das formas culturais constitui um recurso para a criatividade e o futuro da humanidade.

Os Novos Estudos da Infância e os Novos Estudos da Criança apontam para a complexidade teórico-metodológica, para um contínuo diálogo e movimento. Logo, o que este ensaio propõe é um caminho mais horizontal que supere a ênfase na natureza primitiva e no desenvolvimento linear das crianças, cujo ápice é atingido com a entrada na fase adulta. Enfim, trata-se de um entendimento multívoco de criança, com uma diversidade de possibilidades de desenvolvimento que uma criança pode intentar, junto à complexidade de seus pensamentos, as características de sua cognição, o tamanho de seus corpos, a realização de suas astúcias, sua multiplicidade linguageira e o caráter imaginário de sua relação com a realidade que são diferentes dos adultos. 


\section{CHILDHOOD STUDIES, CHILDREN'S STUDIES: WHAT FIELDS? WHAT THEORIES? WHAT QUESTIONS? WHAT METHODS?}

In this article, we perform a theoretical essay on the Childhood Studies and Children's Studies, since its inception until its organization as a field at the intersection between disciplines and questions about childhood and children. At first, we reflect on childhood and child concepts. Then, we place the beginnings of such studies, especially conceptual issues discussed in the early twentieth century, and then, we focus on the challenges of the New Children's and Childhood Studies, such as the links between knowledge and disciplines and the diversity of theoretical traditions. Since researches with small children are newer in this context, we propose some reflections regarding them, and we finalize the article with some challenges, like thinking the rigidity of the boundaries between generations and stages of childhood.

KEYwORDs: Childhood. Children. Childhood Studies. Children's Studies.

\section{ESTUDIOS SOCIALES DE LA INFANCIA, ESTUDIOS DE INFANCIA: ¿QUÉ CAMPOS? ¿QUÉ TEORÍAS? ¿QUÉ PREGUNTAS? ¿QUÉ MÉTODOS?}

RESUMEN: En este artículo, desenvolvemos un ensayo teórico sobre los Estudios Sociales de la Infancia y los Estudios de Infancia, desde su origen hasta su organización como un campo ubicado en la intersección entre disciplinas y preguntas sobre la infancia y los niños. Inicialmente reflexionamos sobre los conceptos de "infancia" y de "niños". Luego, situamos el comienzo de este tipo de estudios, resaltando, especialmente, problemas conceptuales discutidos a principios del siglo $X X, y$, después, nos centramos en los retos de los Nuevos Estudios de la Infancia y la niñez, observándolos como punto de relación entre los diferentes conocimientos y asignaturas y la diversidad de tradiciones teóricas. Como las investigaciones sobre niños y niñas pequeños son más recientes, proponemos algunas reflexiones a respecto, y concluimos este texto con algunos retos, entre ellos, pensar la rigidez de las fronteras entre las generaciones y las etapas de la infancia.

Palabras-clave: Niñez. Niños. Estudios Sociales de la Infancia. Estudios de Infancia.

\section{NOTAS}

1) Disponível em: <http://www.gddc.pt/direitos-humanos/textos-internacionais-dh/tidhuniversais/dc-declaracao-dc.html>. Acesso em: 24 nov. 2015.

2) Disponível em: <http://www.unicef.org/brazil/pt/resources_10120.htm>. Acesso em: 24 nov. 2015. 


\section{REFERÊNCIAS}

ALANEN, L. Editorial: Critical Childhood Studies? Childhood, Trondheim, v. 2, n. 18, p. 147-150, 2011.

ARIÈS, P. História social da criança e da família. Rio de Janeiro: Guanabara, 1986.

BARBOSA, M. C. S. A ética na pesquisa etnográfica com crianças: primeiras problematizações. Práxis Educativa, Ponta Grossa, v. 9, n. 1, p.235-245, jan./jun. 2014.

BRASIL. Estatuto da criança e do adolescente. São Paulo: Cortez, 1990.

COHN, C. Antropologia da Criança. Rio de Janeiro: Zahar, 2005.

CORSARO, W. A. Sociologia da Infância. Porto Alegre: Artmed, 2011.

COUSINET, R. La vida social de losniños: Ensayo de sociologia infantil. Buenos Aires: Editorial Nova, 1953.

DALLARI, D. A. O direito da Criança ao Respeito. São Paulo: Summus, 1986.

DELALANDE, J. La categoria Infancia. Infancia y ciencia social, Lima, n.1, p.1-8, maio 2007.

. Habilitation a diriger des recherches en sciences de l'éducation. Volume 1 - Note de Synthese: contribution a un champ de recherche socio-anthropologique sur l'enfance. Reflexions sur l'alterite et les specificites des enfants face auxadultes. France: Caen, 2009.

. O pátio de recreio: lugar de socialização e de cultura infantis. In: BROUGÈRE, G.; ULMANN, A. L. (Org.). Aprender pela vida cotidiana. Campinas, São Paulo: Autores Associados, 2012. p. 65-79.

ELIAS, N. O processo civilizador - Volume 1: Uma história dos costumes. 2. ed. Rio de Janeiro: Zahar, 2011.

FERNANDES, C. V. Eu gosto de brincar com os do meu tamanho! Culturas infantis e cultura escolar - entrelaçamento para o pertencimento etário na instituição escolar. Dissertação (Mestrado em Educação) - Faculdade de Educação, Universidade Federal do Rio Grande do Sul, Porto Alegre, 2008.

FERREIRA, M; NUNES, A. Estudos da infância, antropologia e etnografia: potencialidades, limites e desafios. Linhas Críticas, v. 20, n. 41, p. 103-123, 2014.

GEERTZ, C. Uma descrição densa: por uma teoria interpretativa da cultura. In: A Interpretação das Culturas. Rio de Janeiro: LTC,1989. p. 13-41.

GOTTLIEB, A. Para onde foram os bebês? Em busca de uma antropologia de bebês (e de seus cuidadores). Psicologia USP, São Paulo, v. 3, n. 20, p. 313-336, jul./set. 2009. GRUZINSKI, S. O pensamento mestiço. São Paulo: Cia das Letras, 2001. 
HONIG, M. S. "How is the child constituted in Childhood Studies?" In: QVORTRUP, J; CORSARO, W; HONIG, M.S (Ed.). The Palgrave Handbook of Childhood Studies. London/NY: Palgrave MacMillian, 2009. p. 63-67.

JENKS, C. The Sociology of Childhood: Essential Readings. London: Batsford, 1982.

KOHAN, Walter. Infância: entre Educação e Filosofia. Belo Horizonte: Autêntica, 2003. LOPES DA SILVA, A; NUNES, A. (Org.). Crianças Indígenas, ensaios antropológicos. São Paulo: Mari/Fapesp/Global, 2002.

MATTTHEWS, Gareth. A filosofia da Infância. Lisboa: Instituto Piaget, 1997.

MAUSS, M. Três observações sobre a sociologia da infância. Pro-Posições, v. 21, n. 3, p. 237-244, dez. 2010.

MIGNOLO, W. Os esplendores e as misérias da "ciência": colonialidade, geopolítica do conhecimento e pluri-versalidade epistémica. In: SANTOS, B. S (Org.). Conhecimento prudente para uma vida decente. Porto: Edições Afrontamento, 2003. p. 631-671.

OTTAVI, D. Ah! Mais, c'estunjeu d'été, ça! La pérennité d'un entre -

enfants étudiée au début du XX siècle par Roger Cousinet. In: DELALANDE, J (Org.). Des enfants entre eux. Des jeux, desrègles, dessecrets. Paris: Éditions Autrement, 2009. p. 12- 28.

PAIS, J. M. Sociologia da vida cotidiana. Teorias, métodos e estudos de caso. Lisboa: Imprensa de Ciências Sociais, 2002.

PLAISANCE, E. Para uma sociologia da pequena infância. Educ. Soc., Campinas, v.25, n.86, p.221-241, abril 2004.

PROUT, A. Reconsiderando a nova Sociologia da Infância. Cadernos de Pesquisa, v. 40, n.141, p.729-750, set./dez. 2010.

QVORTRUP, J. Visibilidades das crianças e da infância. Linhas Críticas, v. 20, n. 41, p. 23-42, 2014.

ROGOFF, B. A natureza cultural do desenvolvimento humano. Porto Alegre: Artmed, 2005.

SANTOS, B. S. Uma cartografia simbólica das representações sociais: prolegômenos a uma concepção pós-moderna do Direito. Revista Crítica das Ciências Sociais, Coimbra, n.24, p.139-172, março 1988.

SARMENTO, M. J. Sociologia da Infância: correntes e confluências. In: ; GOUVEA, M. C. S (Org.). Estudos da Infância. Educação e Práticas Sociais. Petrópolis, Rio de Janeiro: Vozes, 2008. p.17-39.

A sociologia da infância e a sociedade contemporânea: desafios conceituais e praxeológicos. In: ENS, R; GARANHANI, M. (Org.). Sociologia da Infância e a formação de professores. Curitiba: Champagnat, 2013. p. 13-46. 
;PINTO, M. As crianças e a infância: definindo conceitos, delimitando o campo. In:___. (Org.). As crianças contexto e identidades. Braga: Universidade do Minho, 1997. p.9-30.

SIROTA, R.L. L'enfance au regard des sciences sociales. Anthropologie de l'enfance,v.1, p. 1-20, 2011.

TOMÁS, C. "Há muitos mundos no mundo". Cosmopolitismo, Participação e Direitos da Criança. Porto: Edições Afrontamento, 2011.

WOODHEAD, M. F. In: KEHILY, M. (Org.). An Introduction to Childhood Studies. Maidenhead: Open University Press, p. X-XI, 2004.

Maria Carmen Silveira Barbosa: Doutora em educação pela Universidade Estadual de Campinas (2000), Professora Associada da Universidade Federal do Rio Grande do Sul e atua no Programa de Pós-Graduação em Educação na linha de pesquisa estudos sobre as infâncias. Líder de pesquisa no grupo de estudos em Educação Infantil e Infância - GEIN.

E-mail: licabarbosa@uol.com.br

Ana Cristina Coll Delgado: Doutora em Educação pela Universidade Federal Fluminense (2003); Professora Associada da Faculdade de Educação da Universidade Federal de Pelotas e atua no Programa de Pós-Graduação em Educação. Atua como Líder de Pesquisa no Grupo Crianças, Infâncias e Culturas - CIC.

E-mail: anacoll@uol.com.br

Catarina Almeida Tomás: Doutora em Estudos da Criança, área de conhecimento da Sociologia da Infância; docente da Escola Superior de Educação de Lisboa; investigadora do CICS da Universidade do Minho e Grupo de Pesquisa CIC.

E-mail: catarinatomas@smail.com 